|| ISSN(online): 2589-8698 || ISSN(print): 2589-868X ||

International Journal of Medical and Biomedical Studies

Available Online at www.ijmbs.info

PubMed (National Library of Medicine ID: 101738825)

Index Copernicus Value 2018: 75.71

Original Research Article

Volume 3, Issue 7; July: 2019; Page No. 16-17

\title{
INTRACRANIAL DERMOID CYST: A CASE REPORT
}

Dr. Sunita Kumari ${ }^{1}$, Dr. Neelima Arora ${ }^{2}$, Dr. S.P. Vyas ${ }^{3}$, Dr. Kapil Pareek ${ }^{4}$

${ }^{1}$ Junior Resident, ${ }^{2}$ Associate Professor, ${ }^{3}$ Professor, ${ }^{4}$ Assistant Professor,

${ }^{1-3}$ Department of pathology, Sardar Patel Medical College, Bikaner.

${ }^{4}$ Department of Neurosurgery, PBM Hospital, SPMC, Bikaner

Article Info: Received 06 June 2019; Accepted 02 July. 2019

DOI: https://doi.org/10.32553/ijmbs.v3i7.361

Address for Correspondence: Dr. S.P. Vyas, Professor, Department of pathology, Sardar Patel Medical College, Bikaner.

Conflict of interest: No conflict of interest.

\section{Abstract}

Dermoid cyst of brain is a rare tumor arising due to embryogenic defect. It comprises only about $0.3 \%$ of intracranial tumors. A 18 year old female patient was admitted with complaints of seizures since last 6 months. The brain MRI suggested intra-axial dermoid cyst. The patient was operated \& histopathology report confirmed the diagnosis of dermoid cyst.

\section{Introduction:}

Dermoid cyst is a rare lesion comprising only about $0.3 \%$ of intracranial tumors arising from ectodermal elements ${ }^{1}$. Intra-axial dermoid cysts are extremely rare $^{2}$. These cysts are benign lesions and are slow growing which may even encroach the neurovascular structures and do rarely rupture ${ }^{3}$.

They are most commonly discovered during the third to fifth decades of life and usually incidently,after spontaneous or traumatic rupture or when symptoms present from mass-effect. Average sizes tend to be 4 $\mathrm{cm}$ to $4.5 \mathrm{~cm}$ and they grow overtime from the secretion of sebaceous material into the cyst, along with sloughing of epidermal cells ${ }^{4}$. They are believed to arise due to ectopic inclusion of epithelial cells in the course of neural tube closure during embryonic development. Dermoids tend to be midline lesions and contain dermal and epidermal elements including sebum, hair, keratin ${ }^{5}$. We received a rare case of dermoid cyst in right subfrontal region.

\section{CASE HISTORY:}

A 18-year old female was admitted with complaints of seizures since last 6 months. Other sign \& symptoms of raised intracranial tension were absent. Systemic examination revealed no abnormal findings.

\section{Radiological findings:}

The brain MRI, on T1/T2/FLAIR images showed a well defined intra-axial fatty lesion measuring $31 \times 28 \times 27 \mathrm{~mm}$ with peripheral calcification in right subfrontal region. Mass effect evident as mild compression of overlying frontal lobe and mildline shift towards left side and associated fat materials in bilateral sylvian fissures and perimesencephalic cistern. Radiological findings were suggestive of dermoid cyst with rupture.

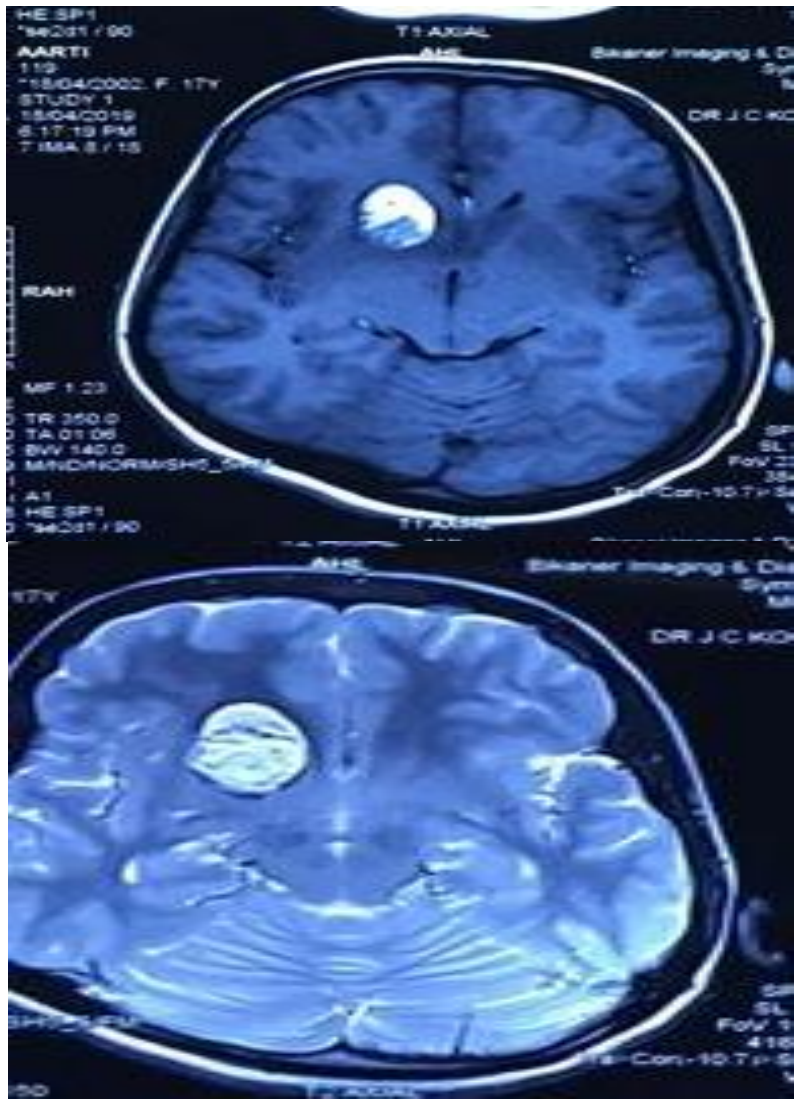

Figure 1: 


\section{Gross findings:}

We received flap like grey white soft tissue pieces collectively measuring $4 \times 1.5 \mathrm{~cm}$ admixed with sebaceous material and hair tufts.

\section{Microscopic Images:}

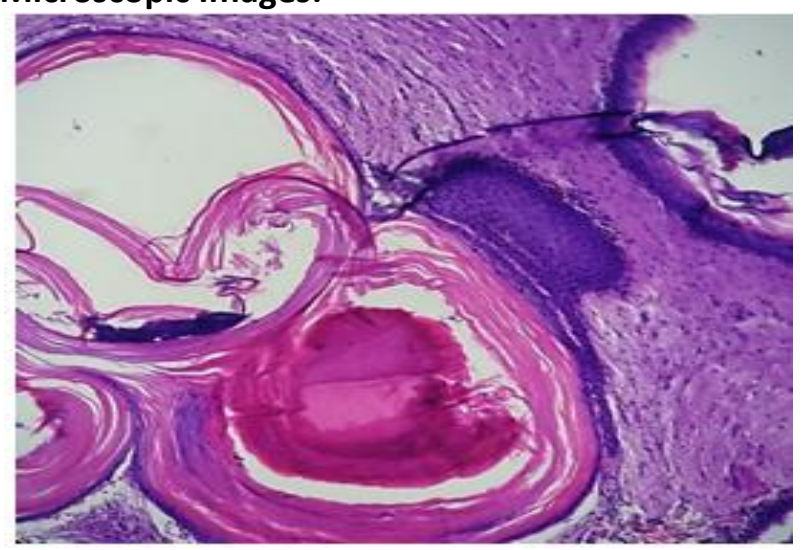

(A)

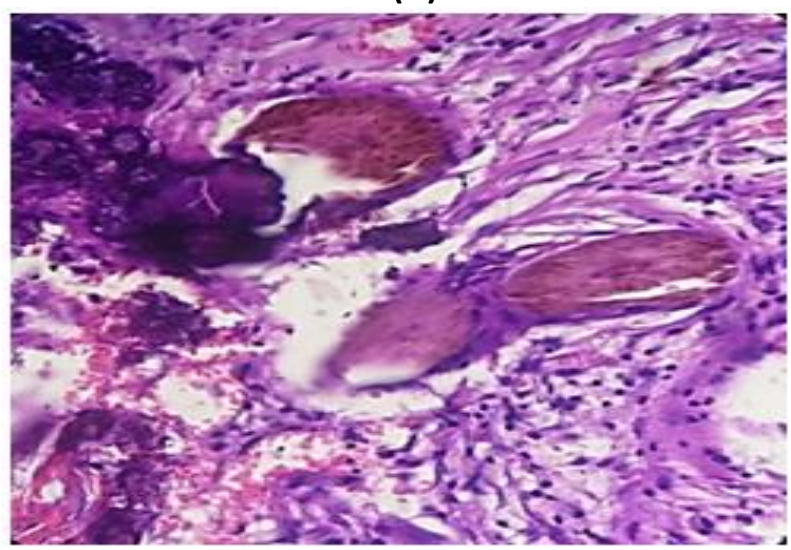

(B)

Figure 2: Microsopic examination of H\&E stained section revealed (a)10x; cyst in brain parenchyma, lined by keratinizing stratified squamous epithelium showing anucleate squames, keratin flakes. (b) $40 x$; hair shafts,foci of calcification.

\section{Discussion:}

Intracranial dermoid cysts are rare benign, slow growing neoplasms commonly occurring at midlines, they arise from ectodermal elements due to implantation of abnormal tissue during neural tube closure during embryogenesis ${ }^{6}$. Based on the cyst location,clinical manifestion can varies. The most common symptom is headache followed by seizures, cerebral ischemia with sensory and/or motor hemi syndrome and aseptic meningitis ${ }^{7}$.

On CT scans, intracranial dermoid cysts are heterogenous, the fat in the cyst appears hypodense, whereas calcification in the wall appears hyperdense. On MRI,dermoid cysts are hyperintense on T1-weighted sequences and variable on T2weighted sequences ${ }^{8}$.

Final diagnosis is made by histopathogigal examination of the specimen obtained by craniotomy and excision of the cyst. On gross, dermoid cysts are well defined rounded masses with a firm outer capsule. On cut section, cysts are filled by a thick,greasy,yellowish sebaceous material with tanged hair.

Histologically, the cysts are lined by a stratified squamous epithelium with keratin formation. Subepithelium shows skin appendages like hair follicles,sweat \& sebaceous glands. In our case, We encountered hair shafts in the subepithelium.

Treatment of dermoid cysts consists of surgical excision which should be as complete as possible.

Differential diagnosis:

1. Epidermoid cysts: They don't have epidermal appendages such as hair follicles, sweat \& sebaceous glands.
2. Lipoma
3. Teratoma
4. Cystic glioma
5. Craniopharyngioma

\section{References:}

1. Dr.Jyoti K. Kudrimoti, Dr. S. Khedkar, Dr. S. Puranik. Intracranial dermoid cyst: A case report. Indian Journal of Basic and Applied Medical Research; September 2014: Vol - 3, Issue- 4, P. 329-331.

2. Velho VL, Khan SW, Agarwal V,Sharma M.Intra-axial CNS dermoid cyst. Asian J Neurosyrg 2012;7:42-4.

3. Osbom AG, Preece MT. Intracranial cysts:raiologicpathologic correlation and imaging approach. Radiology,2006;239(3):650-664.

4. Welte WB, Calnan DR, Gill HS. Rupture Intracranial Dermoid Cyst: A Rare Cause of Post-Partum Seizures. Ann Clin Case Rep. 2018; 3: 1507. ISSN:2474-1655.

5. Thomas M. Triplett, Adam Griffith, Kimmo J. Hatanpaa, Samuel L. Barnett. Demoid Cyst of the Infratemporal Fossa: Case Report and Review of the Literature. J Neurol Surg Rep 2014;75;e33-e37.

6. Obana WG, Wilson CB: Epidermoid cysts of brainstem, Report of three cases. J. Neurosurg 74; 123-128,1991.

7. El Bahy K, Kotb A, Galal A,El-Hakim A. Reptured intracranial dermoid cysts. Acta Neurochir (Wien), 2006; 148(4): 457-462.

8. Sanjay Ballari, Gurubharath I. Intracranial ruptured dermoid cyst presenting as dysarthria:A case report. IAIM,2018; 5(10): 171-178. 